\title{
Datos de base de la vega de Granada y Alhama
}

La zona de la vega de Granada y Alhama comprende sesenta y cinco términos municipales de la provincia de Granada. Cuarenta y nueve de estos municipios se integran completamente en la zona estudiada y son los siguientes: Agrón, Alfacar, Alhama de Granada, Alhendin, Arenas del Rey, Armilla, Atarfe, Beas de Granada, Cacin, Cájar, Calicasas, Cenes de la Vega, Chauhina, Chimeneas, Churriana de la Vega, Cijuela, Cogollos Vega, Cúllar Vega, Dúdar, Escúzar, Fuente Vaqueros, Las Gabias, Granada, Güevéjar, HuétorSantillán, Huétor -Tajar, Huétor -Vega, Jayena, Jun, Láchar, La Malahá, Maracena, Moraleda de Zafayona, Nivar, Ogijares, Otura, Peligros, Pinos-Genil, Pinos-Puente, Pulianas, Quéntar, Salar, Santa Cruz del Comercio, Santa Fe, Vegas del Genil, Ventas de Huelma, Villanueva de Mesía, Viznar y Zafarraya.

Otros dieciséis municipios están integrados parcialmente: Albolote, Albuñuelas, Colomera, Deifontes, Dilar, Gójar, Güéjar Sierra, Illora, Loja, Moclinn, Monachil, Montefrio, Otivar, Padul, Villamena y La Zubia

El total de inmuebles ${ }^{1}$ que se localizan en esta zona son 516 , de los cuales el $65 \%$ corresponde al patrimonio arquitectónico; el $26 \%$, al patrimonio arqueológico; y el 9\%, al patrimonio etnológico.

El porcentaje tan elevado de inmuebles de carácter arquitectónico es lógico pues dentro de la zona estudiada se encuentra el centro histórico de Granada con gran cantidad de bienes culturales muchos de ellos incluidos en el CGPHA, además de La Alhambra, el Generalife y el Barrio del Albaycin, que están declarados por el Comité de Patrimonio Mundial de la UNESCO como patrimonio mundial. Existen también numerosas construcciones militares relacionadas con la defensa del territorio que marcan de cierta manera el paisaje de la vega de Granada.

Dentro de esta tipología edificatoria además del recinto de la Alhambra, están el castillo de Alhama de Granada, el castillo de Illora, o las murallas y el alcázar de Loja. También son determinantes las torres de vigilancia diseminadas por el territorio y situadas en lugares estratégicos. Son interesantes en esta zona las infraestructuras hidráulicas, entre las que se encuentran la acequia de Aynadamar, o los restos del acueducto de Deifontes. Entre los edificios agropecuarios de época romana están la villa romana de Las Gabias, la villa del Pantano en Albolote o la villa romana de Armilla. De época contemporánea hay abundantes ejemplos de cortijos asociados a cultivos hortícolas, así como otros tipos de arquitectura dispersa como son los secaderos de tabaco.

Desde el punto de vista de las tipologías funcionales y los periodos históricos a los que se asocia el patrimonio inmueble de la zona estudiada, se han utilizado los términos del Tesauro de Patrimonio Histórico Andaluz agrupándolos de la siguiente manera:
- Edificaciones productivas: los inmuebles pertenecientes a esta tipología suponen un $18 \%$ del total.

- Edificaciones dotacionales, que agrupa distintas tipologías como las construcciones funerarias, sanitarias, de espectáculo, etc. Los inmuebles pertenecientes a esta tipología suponen un $23 \%$ del total.

- Asentamientos y espacios libres: $11 \%$ del total.

- Edificaciones militares: $11 \%$ del total.

- Edificaciones religiosas: 15\% del total.

- Edificaciones residenciales: 21\% del total.

- Sitios con representaciones rupestres: 1\% del total.

En cuanto a los periodos históricos destaca la Edad Contemporánea, con 160 inmuebles, seguidos de la Edad Moderna, con 122 inmuebles; la Edad Media, con 83 inmuebles; la Prehistoria reciente, con 60 inmuebles; la Época romana, con 44; la Protohistoria, con 15; y por último el Paleolítico, con 8 inmuebles.

Pilar Mondéjar Fernández de Quincoces Salud Soro Cañas

Centro de Documentación y Estudios del IAPH

\section{Notas}

1. La información de carácter patrimonial contenida en el Sistema de Información para la Gestión Integral del Patrimonio Cultural relativa a la zona de la vega de Granada y Alhama se analizara en base al patrimonio inmueble que se haya localizado cartográficamente en la misma.

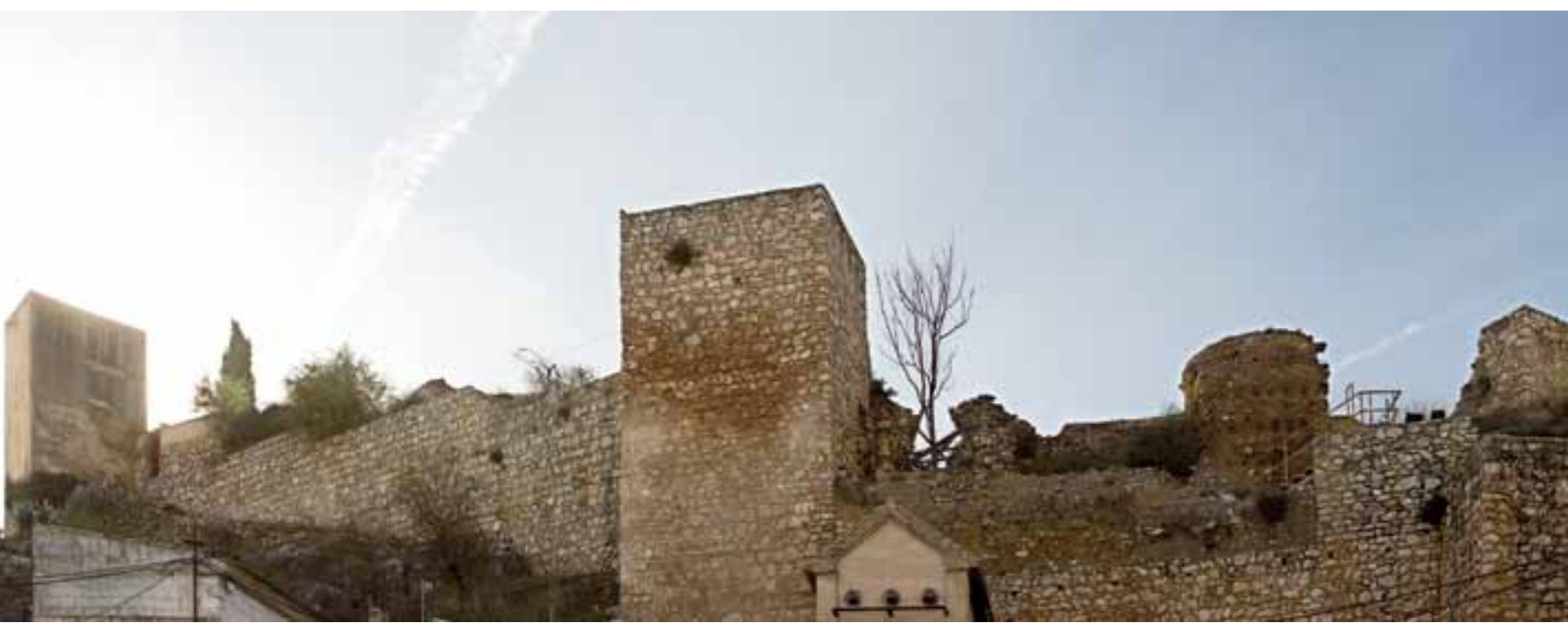

Castillo Fortaleza de illora. Foto: Juan Carlos Cazalla, IAPH 


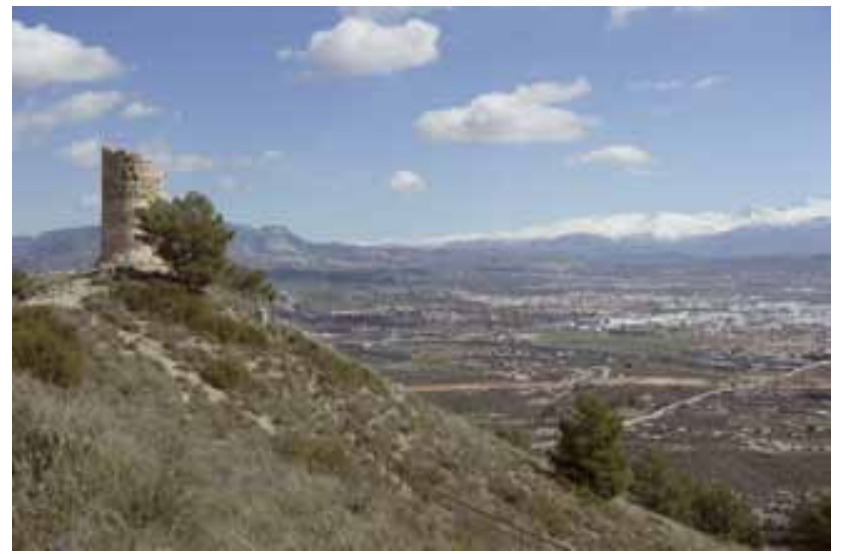

Torreón de Albolote. Foto: Juan Carlos Cazalla, IAPH

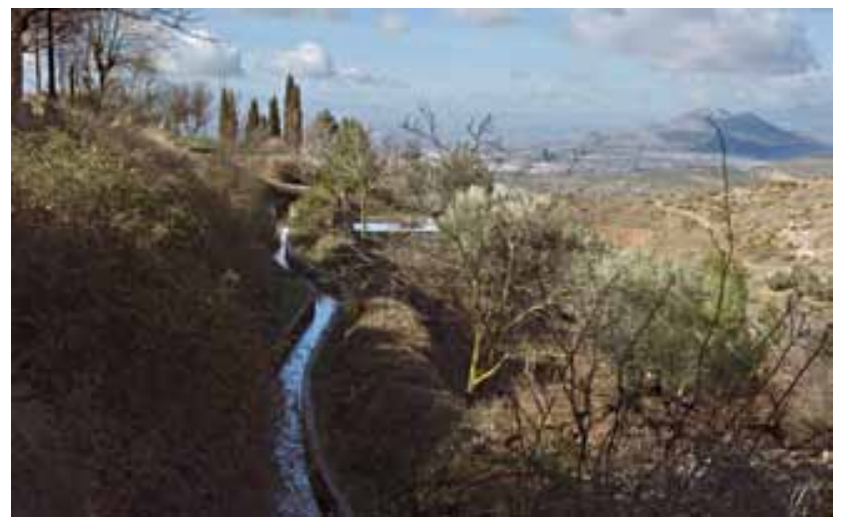

Acequia de Aynadamar. Viznar. Foto: Juan Carlos Cazalla, IAPH
Gráfico 1. Distribución de inmuebles por Tipo de Patrimonio
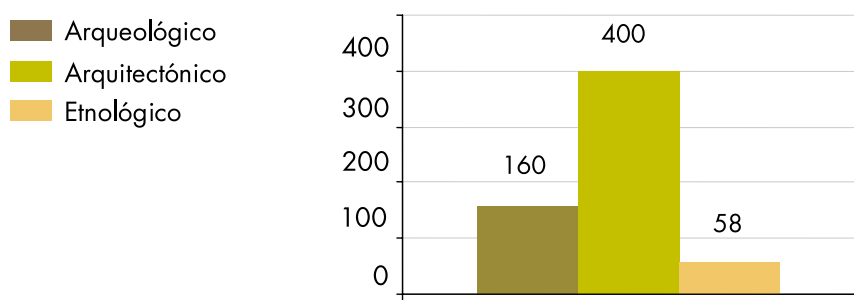

Gráfico 2. Distribución de inmuebles por Tipologías Funcionales
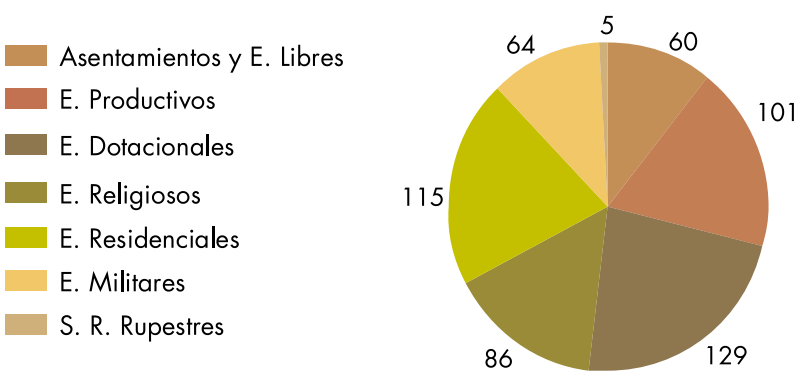

Gráfico 3. Distribución de inmuebles por Periodo Histórico

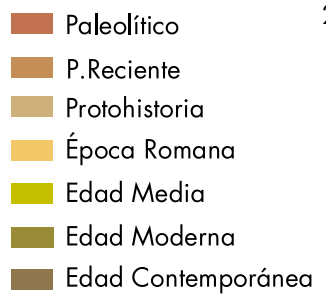

Edad Contemporánea

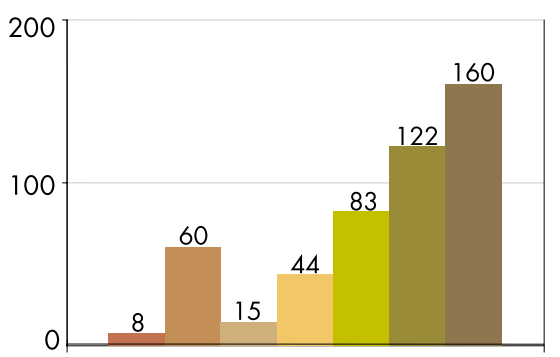

№ Inmuebles

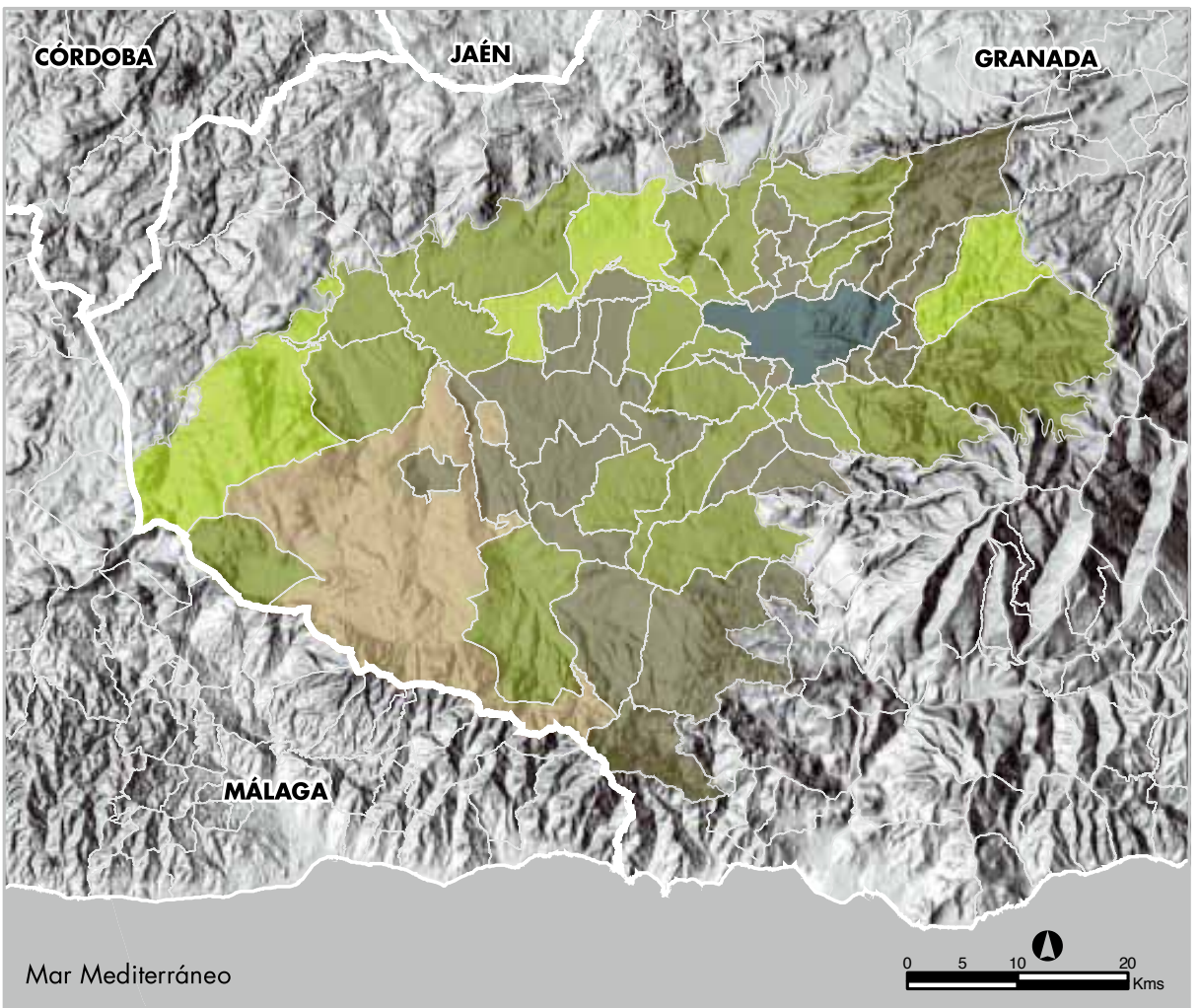

Mapa de distribución del

Patrimonio Inmueble.

Vega de Granada y Alhama

Leyenda

$$
\begin{aligned}
& \text { Municipios } \\
& \text { Masas de ag } \\
& \text { Límites Provinci } \\
& \text { № de Inmuebles } \\
& 0-3 \\
& 4-11 \\
& 12-19 \\
& 20-42 \\
& 43-236
\end{aligned}
$$

Masas de agua

Límites Provinciales

Escala 1:900.000

Proyección UTM USO 30

Localización del área

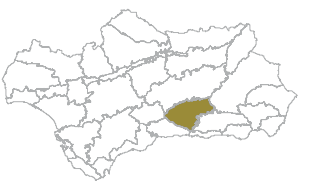

Vega de Granada y Alhama. Distribución del patrimonio inmueble.

Mapa y gráficos: Centro de Documentación y Estudios, IAPH 